\title{
Garlic in health and disease
}

\author{
S. V. Rana ${ }^{1 *}$, R. Pal $^{1}$, K. Vaiphei ${ }^{2}$, Sanjeev K. Sharma ${ }^{1}$ and R. P. Ola ${ }^{1}$ \\ ${ }^{1}$ Department of Gastroenterology, Postgraduate Institute of Medical Education and Research, Chandigarh, India \\ ${ }^{2}$ Department of Histopathology, Postgraduate Institute of Medical Education and Research, Chandigarh, India
}

\section{Abstract}

The present article reviews the historical and popular uses of garlic, its antioxidant, haematological, antimicrobial, hepatoprotective and antineoplastic properties and its potential toxicity (from sulfoxide). Garlic has been suggested to affect several cardiovascular risk factors. It has also been shown that garlic and its organic allyl sulfur components are effective inhibitors of the cancer process. Since garlic and its constituents can suppress carcinogen formation, bioactivation and tumour proliferation, it is imperative that biomarkers be established to identify which individuals might benefit most. Garlic powder, aged garlic and garlic oil have demonstrated antiplatelet and anticoagulant effects by interfering with cyclo-oxygenase-mediated thromboxane synthesis. Garlic has also been found to have synergistic effects against Helicobacter pylori with a proton pump inhibitor. The active compound allicin may affect atherosclerosis not only by acting as an antioxidant, but also by other mechanisms, such as lipoprotein modification and inhibition of LDL uptake and degradation by macrophages. Freshly prepared garlic homogenate protects against isoniazid + rifampicin-induced liver injury in experimental animal models. Several mechanisms are likely to account for this protection.

Key words: Garlic: Antioxidants: Antimicrobials: Antineoplastics: Hepatoprotection

\section{Introduction}

Garlic (Allium sativum) is a popular spice, a remedy for a variety of ailments and is also known for its medicinal uses as an antibiotic, anti-thrombotic and antineoplastic agent. It has been used for thousands of years for culinary, medicinal and spiritual purposes.

\section{Biochemistry}

Potentially active chemical constituents of garlic are:

(a) Sulfur compounds: alliin, allicin, ajoene, allylpropyl disulfide, diallyl trisulfide (DATS), $S$-allylcysteine (SAC), vinyldithiins, $S$-allylmercaptocysteine and others.

(b) Enzymes: alliinase, peroxidases, myrosinase and others.

(c) Amino acids and their glycosides: arginine and others.

(d) Se, Ge, Te and other trace minerals.

Garlic contains at least thirty-three sulfur compounds, several enzymes and seventeen amino acids ${ }^{(1)}$. Additional constituents of intact garlic include steroidal glycosides and lectins ${ }^{(2,3)}$. It contains higher concentrations of sulfur compounds than any other Allium species. The sulfur compounds are responsible both for garlic's pungent odour and many of its medicinal effects.

\section{Chemical changes in garlic}

When garlic is 'damaged', i.e. attacked by microbes, crushed, cut, chewed, dehydrated, pulverised or exposed to water, the vacuolar enzyme alliinase rapidly lyses the cytosolic cysteine sulfoxides (alliin). The transiently formed compound, allicin, comprises $70-80 \%$ of the thiosulfinates. Typically, alliin is converted to allicin by alliinase (Fig. 1). Allicin instantly decomposes to other compounds, such as diallyl sulfide (DAS), diallyl disulfide (DADS), dithiins and ajoene. At the same time, $\gamma$-glutamyl cysteine is converted to SAC, via a pathway other than the alliin-allicin pathway.

The dozens of brands of garlic on store shelves can be classified into four groups, i.e. garlic essential oil, garlic oil macerate, garlic powder and aged garlic extract $(\text { Table } 1)^{(4)}$.

Garlic oil, aged garlic and steam-distilled garlic do not contain significant amounts of alliin or allicin, but contain various products of allicin transformation, among which none appears to have as much physiological activity as

Abbreviations: DADS, diallyl disulfide; DAS, diallyl sulphide; DATS, diallyl trisulfide; GST, glutathione $S$-transferase; ROS, reactive oxygen species; SAC, $S$-allylcysteine; SOD, superoxide dismutase; STAT1, signal transducer and activator of transcription 1.

*Corresponding author: Dr S. V. Rana, fax +91 172 2744401, email svrana25@hotmail.com 


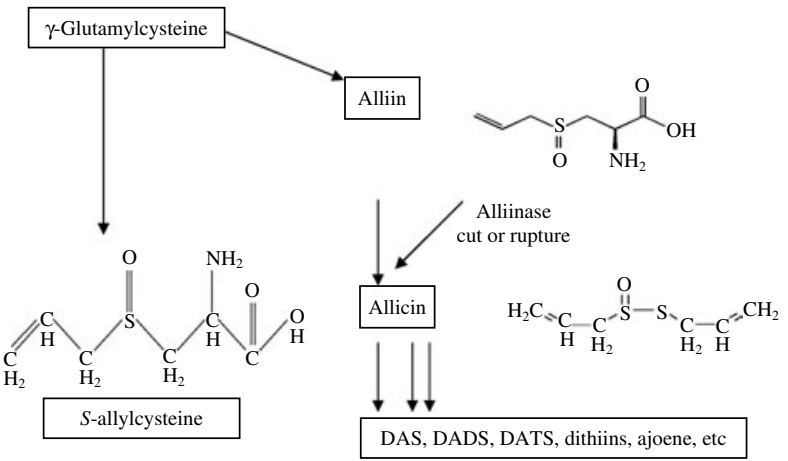

Fig. 1. Chemical changes in garlic. DAS, diallyl sulfide; DADS, diallyl disulfide; DATS, diallyl trisulfide.

fresh garlic or garlic powder ${ }^{(5)}$. In rats, alliin is well absorbed orally, reaching maximum serum concentrations within $10 \mathrm{~min}$, and is excreted within about $6 \mathrm{~h}$. Allicin and vinyldithiins are absorbed more slowly, reaching peak levels between 30 and $120 \mathrm{~min}$ and persisting in the body for up to $4 \mathrm{~d}^{(6)}$. In rats, mice and dogs, SAC is well absorbed (98-100\%) orally ${ }^{(7)}$. Excretion occurs through the renal system and through hepatic breakdown, faecal excretion and exhalation.

\section{Anti-carcinogenic actions of garlic}

Epidemiological and animal studies have shown that consumption of garlic and its allyl sulfur compounds reduces the incidence of cancer, for example, stomach, oesophagus, colon, breast, cervix, skin, uterine and lung cancers ${ }^{(8)}$.

The diverse array of compounds and target tissues involved suggests either that garlic or its associated constituents have multiple mechanisms of action or, more logically, influence a fundamental step in the overall cancer process. Metabolic activation is a necessary event for many of these carcinogens used in animal studies, and possibly for environmental exposures faced by humans. Thus, phase I and II enzymes involved in carcinogen bioactivation and removal may be key in explaining the response to garlic and allyl sulfur compounds. However, few studies have noted significant changes in cytochrome P450 1A1, 1A2, 2B1 or 3A4 activities after supplementation with garlic or related sulfur compounds ${ }^{(9,10)}$. Therefore, other enzymes involved in the bioactivation or removal of carcinogenic metabolites may play a role.

Singh et al. provided evidence that the efficacy of various organosulfides to suppress benzo(a)pyrene tumorigenesis correlated with their ability to suppress NAD(P)H:quinone oxidoreductase, an enzyme involved with the removal of quinones associated with this carcinogen ${ }^{(11)}$. Depressed carcinogen bioactivation because of reduction in cyclooxygenase and lipoxygenase activity may also account for some of the lower incidence of tumours after treatment with some carcinogens ${ }^{(12,13)}$. Enhanced glutathione availability and an elevation in the activity of specific glutathione $S$-transferase (GST), both factors involved in phase II detoxification, may also be significant in the protection provided by garlic and associated allyl sulfur components. Ingestion of garlic by rats increases the activity of GST in both liver and mammary tissue ${ }^{(9,14)}$. It should be noted that not all GST isozymes are influenced equally. Hu et al. provided evidence that the induction of GST $\pi$ may be particularly important in the anticarcinogenic properties associated with garlic and allyl sulfur components ${ }^{(15)}$

\section{Medical uses of garlic}

More than 3000 publications in the past have confirmed the efficacy of garlic for the prevention and treatment of a variety of diseases, acknowledging and validating its traditional uses. It may influence the risk of heart disease and is also used for the treatment of fatigue, although the mechanism involved remains unclear. The anti-fatigue function of garlic may be closely related to its many favourable biological and pharmacological effects ${ }^{(16)}$. Garlic has historically been used to treat aches and pains, leprosy, deafness, diarrhoea, constipation, parasitic infection and fever and to relieve stomachache ${ }^{(17)}$. It has also been used to lower blood pressure, food poisoning, tumours and as a mild anticoagulant ${ }^{(18)}$. Arabian herbalists use garlic to treat abdominal pain, infantile colic, diarrhoea, diabetes, eye infections, snake bites, dandruff and tuberculosis $^{(19)}$. In Ayurvedic medicine, garlic is used to treat respiratory problems, colic and flatulence. Garlic oil drops are used to treat earache ${ }^{(20)}$. Louis Pasteur demonstrated garlic's antiseptic activity in 1858. In African countries, it is also used to treat dysentery ${ }^{(21)}$. Garlic is commonly used to treat chronic bronchitis, recurrent upper respiratory tract infections and influenza ${ }^{(22)}$. In India and Europe, garlic remedies are used to treat coughs, colds, hay fever and asthma ${ }^{(23)}$

\section{Antioxidant actions of garlic}

Protection with aged garlic extract and Nigella sativa oil has been shown to prevent most of the haematological

Table 1. Main brands of garlic on the market

\begin{tabular}{ll}
\hline Type of product & Main compounds and characteristics \\
\hline Garlic essential oil & Only 1\% oil-soluble sulfur compounds (for example, DAS or DADS) in 99\% vegetable oil. No water-soluble fraction \\
Garlic oil macerate & Oil-soluble sulfur compounds and alliin, no allicin \\
Garlic powder & Allicin and a small amount of oil-soluble sulfur compounds \\
Aged garlic extract & Mainly water-soluble compounds (for example, SAC or saponins), small amount of oil-soluble sulfur compounds \\
\hline
\end{tabular}

DAS, diallyl sulfide; DADS, diallyl disulfide; SAC, S-allylcysteine. 
and biochemical changes and to markedly improve the antioxidant capacity of schistosomiasis-infected mice compared with infected-untreated ones. The antioxidant and antischistosomal action of aged garlic extract and $N$. sativa oil was greatly diverse according to treatment regimen $^{(24)}$

Garlic oil could be an effective agent or food supplement in reducing the toxicity of tributyltin ${ }^{(25)}$. Allicinmediated lipoperoxide production in fungal plasma membranes is the cause of the enhancement in the cellular uptake of polymyxin $\mathrm{B}$ as well as its action against the vacuole $^{(26)}$. Supplementation of garlic oil at $5 \mathrm{mg} / \mathrm{kg}$ body weight has been shown to have an anticoagulation effect in an animal study ${ }^{(27)}$

Whole garlic and aqueous garlic extract exhibit direct antioxidant effects and enhance the serum levels of two antioxidant enzymes: catalase and glutathione peroxidase $^{(28)}$. Garlic extract and allicin efficiently scavenged exogenously generated hydroxyl radicals in a dosedependent fashion ${ }^{(29)}$. Other garlic constituents, such as SAC, also demonstrated significant antioxidant effects in vitro ${ }^{(30)}$. The sulfur compounds found in fresh garlic appear to be nearly 1000 times more potent as antioxidants than those found in aged garlic extract ${ }^{(31)}$.

Garlic (both the 10\% homogenate in physiological saline solution and its supernatant fraction) was able to reduce the radicals that were generated by the Fenton reaction and trapped by phenyl-butyl-nitron; radicals present in cigarette smoke were also reduced by garlic $^{(32)}$. In rat liver microsomes, garlic extract prevented the formation of thiobarbituric acid-reactive substances in cell membranes during lipid peroxidation in a dose dependent fashion $^{(33)}$. An aqueous extract obtained from $1 \mathrm{mg}$ of a garlic preparation was as effective as an antioxidant as $30 \mathrm{nmol}$ ascorbic acid and/or $3.6 \mathrm{nmol} \alpha$-tocopherol ${ }^{(34)}$. Glycation endproduct formation is increased under conditions of oxidative stress, such as glutathione depletion, and glycated proteins produce 50-fold more toxic free radicals than non-glycated proteins. A recent study suggested that aged garlic extract inhibits the formation of glycation endproducts in vitro and the formation of glycation-derived free radicals ${ }^{(35)}$.

Garlic and its constituents protect tissue against oxidative damage and improve organ functions in various animal models ${ }^{(36)}$. In male Wistar rats, administration of garlic extract against nicotine hydrogen bitartrate for $21 \mathrm{~d}$ increased glutathione levels and decreased malondialdehyde levels in aorta, heart, kidney and urinary bladder tissues $^{(37)}$. Aqueous garlic administration protects the tissues against nicotine-induced oxidative damage and improves renal function and histological damage. Similarly, oral administration of garlic oil in carbon tetrachlorideintoxicated rats significantly decreases the tissue lipid profile, lipid peroxidation levels, alkaline phosphatase, serum transaminases and protects the liver from damage by carbon tetrachloride as effectively as vitamin E.
These changes induced by garlic oil in these rats are comparable with that of vitamin $\mathrm{E}^{(38)}$. DAS, DADS and DATS are principal constituents of garlic. The effect of these sulfides on phase II drug-metabolising enzymes and on the rat model of acute liver injury induced by carbon tetrachloride has been studied. A highly purified form of each sulfide was administered to rats at a concentration of 10 or $100 \mu \mathrm{mol} / \mathrm{kg}$ body weight for 14 consecutive days. DATS $(10 \mu \mathrm{mol} / \mathrm{kg})$ and DADS $(100 \mu \mathrm{mol} / \mathrm{kg})$ significantly increased the activities of GST and quinone reductase, whereas DAS did not. In the rat model of carbon tetrachloride-induced acute liver injury, DATS $(10 \mu \mathrm{mol} / \mathrm{kg})$ significantly suppressed the increase in plasma lactate dehydrogenase and serum glutamate oxaloacetate transaminase activities. Therefore, hepatic phase II enzymes were induced strongly by the trisulfide and weakly by the disulfide, but not by DAS. DATS significantly reduced the liver injury caused by carbon tetrachloride. DATS may be one of the important factors in garlic oil that protects our body against the injury caused by radical molecules ${ }^{(39)}$.

Another study showed the modifying effects of aqueous extracts of garlic and neem leaf during the pre-initiation and post-initiation phases of gastric carcinogenesis induced by $N$-methyl- $N^{\prime}$-nitro- $N$-nitrosoguanidine in rats. Enhanced lipid peroxidation in the liver and blood of tumour-bearing animals was accompanied by significant decreases in the activities of glutathione-dependent antioxidants in the pre-initiation as well as in the post-initiation phases, but these alterations were reduced by combined supplementation of garlic and neem. It was suggested that the modulatory effects of garlic and neem leaf on hepatic and blood oxidant-antioxidant status may play a key role in preventing cancer development at extra-hepatic sites $^{(40)}$. SAC, a water-soluble compound of garlic, also has been shown to have antioxidant activity in experimental animals. Much experimental evidence suggests that the actions of quinolinic acid also involve reactive oxygen species (ROS) formation and oxidative stress as major features of its pattern of toxicity. The effect of a garlic-derived compound and well-characterised free radical scavenger, SAC, on quinolinic acid-induced striatal neurotoxicity and oxidative damage has been studied in rats. SAC at a dose of $150 \mathrm{mg} / \mathrm{kg}$ resulted effective to prevent quinolinateinduced lipid peroxidation, whereas the systemic administration of $300 \mathrm{mg} / \mathrm{kg}$ of this compound to rats decreased effectively the quinolinic acid-induced oxidative injury measured as striatal ROS formation and lipid peroxidation. SAC $(300 \mathrm{mg} / \mathrm{kg})$ also prevented the striatal decrease of $\mathrm{Cu} / \mathrm{Zn}$-superoxide dismutase (SOD) activity produced by quinolinate. In addition, SAC, at the same dose tested, was able to reduce the quinolinic acid-induced neurotoxicity evaluated as circling behaviour and striatal morphological alterations. SAC ameliorates the in vivo quinolinate striatal toxicity by a mechanism related to its ability to: (a) scavenge free radicals, (b) decrease oxidative 
stress and (c) preserve the striatal activity of $\mathrm{Cu} / \mathrm{Zn}$-SOD. This antioxidant effect seems to be responsible for the preservation of the morphological and functional integrity of the striatum ${ }^{(41)}$. Aged garlic extract, through its scavengenig property on oxidants, increases SOD, catalase, glutathione peroxidase and glutathione levels, and inhibits lipid peroxidation and inflammatory prostaglandins in CVD and dementia ${ }^{(42)}$.

Garlic increases cellular glutathione in a variety of cells including those in normal liver and mammary tissues ${ }^{(43)}$. The ability of garlic to increase glutathione peroxidase and other ROS-scavenging enzymes is important in radioprotection and UV suppression of certain forms of immunity $^{(44)}$.

Oxidative stress and increased systemic inflammation may contribute to endothelial dysfunction. Aged garlic extract containing antioxidant compounds increases NO production and decreases the output of inflammatory cytokines from cultured cells. A recent study showed the effect of treatment with aged garlic extract on brachial artery flow-mediated endothelium-dependent dilation and circulating markers of oxidative stress and systemic inflammation in fifteen men with 2 weeks of treatment. During aged garlic extract supplementation, endotheliumdependent dilation increased (44\%) significantly from baseline and mainly in men with lower baseline endothelium-dependent dilation. Levels of endotheliumdependent dilation at the end of aged garlic extract treatment were significantly higher compared with the corresponding levels at the end of placebo treatment. Although markers of oxidative stress (plasma oxidised LDL and peroxides), systemic inflammation (plasma C-reactive protein and IL-6) did not change significantly during the study, short-term treatment with aged garlic extract may improve impaired endothelial function in men with coronary artery disease treated with aspirin and statin ${ }^{(45)}$.

Short-term garlic supplementation may have a protective role in hypertensive patients and on indices of oxidative stress. Garlic pearls at a dose of $250 \mathrm{mg} / \mathrm{d}$ for 2 months in hypertensive patients were found to decrease lipids and lipoprotein subfractions, plasma-oxidised LDL, plasma and urinary concentrations of 8 -iso-PG F2 $\alpha$ as a biomarker of oxidative stress and increase total antioxidant status. With 2 months of garlic pearl supplementation, there was also a significant decline in both systolic and diastolic blood pressures. It could be suggested that dietary supplementation of garlic may be beneficial in reducing blood pressure and oxidative stress in hypertensive individuals $^{(46)}$.

Epidemiological as well as laboratory studies have shown that garlic consumption reduces the incidence of cancer in the stomach, colon, mammary glands, cervix, etc. Some of the hypothesised mechanisms of the anticarcinogenic effects of garlic are: (i) scavenging of free radicals, (ii) increasing glutathione levels, (iii) increasing the activities of GST and catalase, (iv) inhibition of cytochrome p450 2E1, (v) DNA repair and prevention of chromosomal damage ${ }^{(47)}$. Durak et al. $^{(48)}$ showed that the ingestion of garlic extract $(1 \mathrm{ml}$ garlic extract/ $\mathrm{kg}$ body weight daily for 6 months) leads to significantly lowered plasma and erythrocyte malondialdehyde levels in atherosclerotic patients, even in the absence of changes in antioxidant enzyme activities. They also demonstrated the presence of oxidant stress in blood samples from patients with atherosclerosis which was eliminated by ingesting garlic extract. Thus, it is possible that reduced peroxidation processes may play a part in some of the beneficial effects of garlic in atherosclerotic diseases. In addition, the relationship between the effects of garlic extract supplementation on the blood lipid profile and oxidant-antioxidant status in hypertensive patients suggests a protective effect.

\section{Antilipaemic actions of garlic}

Garlic has demonstrated effects on several risk factors for CVD-hyperlipidaemia, hypertension and platelet aggregation $^{(49)}$. Its anti-atherosclerotic properties are mainly attributed to allicin, which is produced upon crushing of the garlic clove. By using a pure allicin preparation, Gonen et al. were able to show that allicin may affect atherosclerosis not only by acting as an antioxidant, but also by other mechanisms, such as lipoprotein modification and inhibition of LDL uptake and degradation by macrophages ${ }^{(50)}$.

In rat hepatocytes, garlic paste, garlic oil, allicin and ajoene were found to significantly reduce cholesterol biosynthesis by inhibiting 3-hydroxy-3-methylglutaryl (HMG)-CoA reductase and $14-\alpha$-demethylase ${ }^{(51)}$. Some authors postulate that garlic's trace minerals, such as Te, also inhibit hepatic cholesterol synthesis ${ }^{(52)}$. But most attribute garlic's antilipaemic effects to DADS, a decomposition product of allicin ${ }^{(53)}$.

Garlic lowers hyperlipidaemia in animal studies ${ }^{(38)}$. In rats, both garlic and garlic oil have been shown to exhibit significant lipid-lowering effects, primarily through a decrease in hepatic cholesterogenesis ${ }^{(54)}$. Rats that were on an atherogenic diet were supplemented with freezedried garlic powder; garlic exerted a dose-effect response, with the highest doses lowering serum cholesterol significantly, enhancing the ratio of HDL-cholesterol:LDLcholesterol $^{(55)}$. Chickens whose diets were supplemented with garlic powder had significant reductions of plasma and tissue cholesterol and plasma $\mathrm{TAG}^{(56)}$. Garlic supplementation also significantly decreased HMG-CoA reductase activity and cholesterol $7 \alpha$-hydroxylase activity $^{(57)}$. In an experimental model, where rabbits were fed with a high-cholesterol diet supplemented with garlic or allicin, hypercholesterolaemia was significantly inhibited by $50 \%$, indicated by decreased tissue cholesterol, LDL concentrations, raised HDL concentrations, and reduced atheromatous changes ${ }^{(58)}$. Garlic also provided significant 
protection for the enzymes of the glutathione-dependent peroxide detoxification system, which is strongly impaired under hypercholesterolaemia ${ }^{(59)}$. In another study, rats were given garlic, ginger or garlic and ginger supplements for 4 weeks. All groups exhibited significant decreases in blood glucose, serum total cholesterol and serum alkaline phosphatase. Cholesterol was significantly decreased in animals fed with a combination of the two, compared with either alone, indicating that a combination of garlic and ginger is much more effective in reducing blood glucose and serum lipids ${ }^{(60)}$. Since 1975 , many human studies have evaluated garlic's lipid-lowering effects. Controlled trials in healthy adults given garlic supplementation along with cholesterol-rich diets suggest that garlic can reduce mean serum cholesterol levels and increase fibrinolytic activity $^{(48)}$. Although the quality of randomised trials has been only modest, recent meta-analyses have concluded that in over a dozen trials published between 1979 and 1993, there was an average improvement in serum cholesterol concentrations of $9-12 \%$ and a significant reduction in serum TAG in hyperlipidaemic patients taking standardised garlic powder supplements of 600-900 mg daily, with improvement evident within 1 month $^{(61)}$. In a single-blind, placebo-controlled cross-over study, forty hypercholesterolaemic adults were assigned to either placebo for 1 month or fish oil with garlic powder (1200 mg) capsules daily for 1 month. Supplementation with garlic resulted in an $11 \%$ decrease in cholesterol, a $34 \%$ decrease in TAG, and a 10\% decrease in LDL levels, as well as a $19 \%$ decrease in cholesterol/HDL risk ${ }^{(62)}$.

In cell cultures, aqueous solutions of dried garlic powder containing allicin and ajoene have been found to significantly inhibit the proliferative activity of smooth muscle cells from atherosclerotic aortic plaques ${ }^{(63)}$. In hypercholesterolaemic rabbits, garlic supplements significantly reduced the aortic lesions and lipid content of existing fatty plaques ${ }^{(64)}$. In a randomised placebo-controlled trial in ten healthy adults, there was a significant improvement in plasma viscosity and capillary blood flow within $5 \mathrm{~h}$ of taking $900 \mathrm{mg}$ of standardised garlic powder ${ }^{(65)}$. In a prospective 4-year clinical trial of patients treated with $900 \mathrm{mg}$ daily of standardised garlic powder, there was a $9-18 \%$ reduction in plaque volume, a $4 \%$ decrease in LDL levels, an $8 \%$ increase in HDL concentrations and a $7 \%$ decrease in blood pressure ${ }^{(66)}$.

\section{Hepatoprotective actions of garlic}

Garlic oil constituents, particularly DAS, activate constitutive androstane receptor (CAR) and nuclear factor E2-related factor 2 (Nrf2) to induce drug-metabolising enzymes ${ }^{(67)}$.

SAC decreases $\mathrm{CCl}_{4}$-induced liver injury by attenuation of oxidative stress, and can be a useful regimen for chronic liver disease ${ }^{(68)}$. Freshly prepared garlic homogenate has been shown to protect against isoniazid + rifampicin-induced liver injury in an experimental animal model $^{(69)}$. In rat liver cultures, garlic administration before exposure to hepatotoxins (such as carbon tetrachloride, galactosamine and doxorubicin) provided protection against histological and biochemical evidence of damage ${ }^{(70)}$.

In mice, rats and chickens, pretreatment with oral garlic supplements provided significant protection against the toxicity of known hepatotoxins, including heavy metals $^{(71,72)}$. In toads and rats, pretreatment with garlic protected against aflatoxin- and chemically induced liver tumours ${ }^{(73)}$. Aged garlic and garlic's diallyl sulfur compounds protected against acute chemically induced hepatotoxicity in rats ${ }^{(74)}$.

In rats, daily pretreatment with garlic oil against buthionine sulfoximine and carbon tetrachloride effectively prevented increases in plasma aminotransferases and lactate dehydrogenase activities, liver injuries as evidenced by elevations in central necrosis, hepatocyte degeneration and inflammation and increases in plasma TAG contents ${ }^{(36)}$. In the carbon tetrachloride-induced acute liver injury model of rats, DADS and DATS given at a higher dose $(100 \mu \mathrm{mol} / \mathrm{kg})$, by increasing the activities of GST, quinone reductase, and the antioxidative enzyme glutathione peroxidase, reduced the injury caused by the induction of phase II enzymes with carbon tetrachloride ${ }^{(39)}$. Garlic reduced the toxic effects exerted by carbon tetrachloride in other organs in rats, through inhibition of the cytochrome $\mathrm{P} 450$ system that activates carbon tetrachloride into its active metabolite, the trichloromethyl radical ${ }^{(75)}$. In ischaemia and reperfusion injury, garlic has been shown to have a protective effect. Aqueous garlic extract ( $1 \mathrm{ml} / \mathrm{kg}$ ) was given to Wistar albino rats during an ischaemia and reperfusion period. Liver transaminases, malondialdehyde levels, glutathione levels, myeloperoxidase activity and hepatic collagen content, as a fibrosis marker, were increased in the ischaemia and reperfusion group. But these changes were reduced back to control levels by the aqueous garlic extract treatment. Therefore, aqueous garlic extract administration alleviated the ischaemia-reperfusion-induced injury of the liver and improved hepatic structure and function. It seems likely that garlic extract, with its antioxidant and oxidantscavenging properties, may be of potential therapeutic value in protecting the liver against oxidative injury due to ischaemia-reperfusion ${ }^{(37)}$.

In another study, induced liver fibrosis in male Wistar albino rats by bile duct ligation was reduced by aqueous garlic extract. It seems that aqueous garlic extract with its antioxidant and antifibrotic properties protects the liver from oxidative injury resulting in fibrosis ${ }^{(76)}$. In one case report, a patient with severe hepatopulmonary syndrome, who failed somatostatin therapy and declined liver transplantation, began taking large daily doses of powdered garlic. She experienced partial palliation of her symptoms and some objective signs of improvement over 18 months of continuous self-medication ${ }^{(77)}$. 


\section{Other potential effects of garlic}

Haematological effects

In a study on horses, the ability of a herbal composite containing garlic, white horehound, boneset, aniseed, fennel, licorice, thyme and hyssop to reduce the clinical signs of recurrent airway obstruction was investigated; it was hypothesised that the product would safely reduce signs and would improve the inflammatory cell profile within the lungs ${ }^{(78)}$. It has been reported by Wojcikowski et al. ${ }^{(79)}$ that garlic oil should not be relied on in individuals in which reduction in platelet aggregation is desired.

Fresh garlic, garlic powder, aged garlic and garlic oil have demonstrated antiplatelet and anticoagulant effects by interfering with cyclo-oxygenase-mediated thromboxane synthesis ${ }^{(33)}$. Garlic compounds contributing to the anti-thrombotic effect were: alliin, ajoene, allicin, vinyldithiins and DADS ${ }^{(80)}$. These effects appear to be important contributors to garlic's beneficial role in atherosclerotic conditions $^{(81)}$.

\section{Antimicrobial effects}

Garlic oil and allyl alcohol, both derived from alliin in garlic using different preparation methods, cause potent growth inhibition in yeasts ${ }^{(82)}$. The Gram-negative diarrhoeagenic pathogens from stool samples were highly sensitive to garlic, while ciprofloxacin was most effective against Escherichia coli ${ }^{(83)}$. The antimicrobial activity was compromised by storage and heating; therefore it is advisable to use fresh garlic and avoid boiling it for more than 5 min during cooking ${ }^{(84)}$. Chopped garlic has a slowingdown effect on microbiological growth in ground meat depending on the garlic concentration, but this effect was not at an expected level even at the highest concentration, because potential antimicrobial agents in chopped garlic were probably insufficiently extracted ${ }^{(85)}$. Garlic cloves have antimicrobial properties in vitro against streptococci and anticariogenic properties against oral micro-organisms in spite of their adverse effects ${ }^{(86)}$. Fresh garlic and garlic powder, through their combined antioxidant and antimicrobial effects, are potentially useful in preserving meat products $^{(87)}$. A wide variety of these organosulfur compounds, whether naturally occurring or synthetic, exhibit antibacterial properties. Mechanistically, organosulfur groups in garlic compounds can act as metal chelators, powerful nucleophiles or electrophiles depending on the local environment in which a given reaction occurs ${ }^{(88)}$.

Garlic is nicknamed 'Russian penicillin' for its widespread use as a topical and systemic antimicrobial agent $^{(89)}$. Crude garlic extracts exhibited activity against both Gram-negative and Gram-positive bacteria at room temperature, but there were no significant effects if the garlic had been boiled for $5 \mathrm{~min}$ before testing ${ }^{(90)}$. Aged garlic extract demonstrated dose-dependent antimicrobial activity against three different reference strains of Helicobacter pylori at concentrations of $2-5 \mathrm{mg} / \mathrm{ml}$; however, heat treatment of the extracts reduced the anti-bacterial effects $^{(91)}$. Garlic was also found to have synergistic effect against $H$. pylori with a proton pump inhibitor ${ }^{(92)}$. Garlic inhibited the growth of twenty different strains of intracellular Mycobacterium avium isolated from AIDS patients and non-AIDS patients ${ }^{(93)}$. In rabbits, aqueous garlic extract and allicin had significant antibacterial activity against Shigella flexneri, fully curing the infected rabbits within $3 \mathrm{~d}$ compared with a mortality rate of $80 \%$ within $48 \mathrm{~h}$ in the untreated rabbits; antibacterial activity against the challenge strain was observed in the sera of the treated rabbits within 30-60 min of administration of the agent ${ }^{(94)}$.

\section{Antineoplastic effects}

$S$-allylmercaptocysteine (SAMC) may promote docetaxelinduced cell death through promoting G2/M cell cycle arrest and apoptosis. The study by Howard et al. implies a potential role for SAMC in improving docetaxel-based chemotherapy for the treatment of hormone-refractory prostate cancer ${ }^{(95)}$. With the dynamic expression of cyclin B1, DADS induces reversible cell cycle arrest in the G2/M phase of HCT-116 cells through a p53-independent mechanism ${ }^{(96)}$.

Garlic has been known to have anti-inflammatory, anticancer and antioxidant effects. Owing to these effects, garlic and its preparations have been used for the treatment of prostate cancer and relief of benign prostatic hyperplasia symptoms for decades ${ }^{(97)}$. DAS can effectively check the mutations induced by environmental toxicants, as reported by Nigam \& Shukla ${ }^{(98)}$. The protective effects of high doses of garlic oil were more pronounced as compared with those in a vitamin E-administered group ${ }^{(99)}$.

The results demonstrated that DADS induced the expression of signal transducer and activator of transcription 1 (STAT1), which was also confirmed using Western blotting. STAT1 decoy oligonucleotides were also used to block STAT1 mRNA and led to a decrease in the levels of STAT1 and to a subsequent decrease in the percentage of apoptosis induced by DADS in examined colo 205 cells $^{(100)}$. Polybutylcyanoacrylate nanoparticles of DATS (DATS-PBCA-NP) were found to have a good prolonged release effect in vivo and hepatic-targeted activity, and a significant anti-tumour effect on the orthotopic transplantation hepatocellular carcinoma model in mice in association with the suppression of proliferation and the induction of apoptosis of tumour cells. These advantages are probably due to their liver-targeting characteristics and consequently bring a higher anti-tumour activity ${ }^{(101)}$ Garlic compounds induced apoptosis in glioblastoma cells due to the production of ROS, increase in endoplasmic reticulum stress, decrease in $\Delta \psi_{\mathrm{m}}$, and activation of stress kinases and cysteine proteases ${ }^{(102)}$. 
The promising chemopreventive nature of liposomal DAS may form the basis for establishing effective means of controlling various forms of cancer, including skin papilloma ${ }^{(103)}$. DAS is capable of acting efficiently and selectively only in the liver and can be used for hepatoprotection during chemotherapy ${ }^{(104)}$. DADS is an effective antifungal agent able to trigger cell death in Candida, most probably by eliciting oxidative stress as a consequence of thiol depletion and impaired mitochondrial function $^{(105)}$. The ubiquitous efficiency of Z-ajoene, a new compound, has been demonstrated to fight against cancers of various origins including those that harbour viruses $^{(106)}$. The role of oxidative stress and its relation to tumour promotion suggest protective effects of garlic oil against ferric nitrilotriacetate-induced hepatic toxicity and that it can serve as a potent chemopreventive agent to suppress oxidant-induced tissue injury and carcinogenesis ${ }^{(107)}$.

Garlic and its extracts appear to protect against DNA damage in vitro. In animal and epidemiological studies, garlic is associated with a reduced risk of cancer ${ }^{(108)}$. At least two anti-carcinogenic agents have been identified in garlic: DAS and $\mathrm{GST}^{(109)}$. In the glandular stomach mucosa of rats, pretreatment with DAS significantly and dose dependently inhibited chemically induced nuclear aberrations and ornithine decarboxylase activity ${ }^{(110)}$. Similarly, oral administration of a garlic supplement inhibited the development of benzopyrene-induced neoplasia and induced increased GST activity in the forestomach ${ }^{(111)}$. In a study, supplementation with high-Se garlic before exposure to a known carcinogen significantly reduced DNA damage, normalised hepatic enzymes, and increased the concentrations of GST and uridine 5'-diphosphateglucuronyltransferase in the liver and kidney, thus suggesting that garlic may suppress tumour development by enhancing detoxification ${ }^{(112)}$.

Effects of garlic have been summarised in Fig. 2 .

\section{Potential toxicity of garlic}

At present, there are no known toxic compounds in garlic and its extracts. Chronic administration of garlic powder $(50 \mathrm{mg} / \mathrm{d})$ resulted in inhibition of spermatogenesis in rats. Reduced concentration of sialic acid in the testes, epididymis and seminal vesicles together with decreased leydig cell function reflect anti-androgenic effects of garlic $^{(113)}$. A higher concentration of garlic powder $(200 \mathrm{mg} / \mathrm{ml})$ or allicin isolated from garlic caused considerable cell injuries in the portal hepatic zone in isolated perfused rat liver ${ }^{(114)}$, which was not observed at a lower concentration.

Another in vitro study showed that DAS at $5 \mathrm{~mm}$ significantly decreased cell viability in the liver ${ }^{(115)}$. This evidence suggests the cautious use of garlic in animals to monitor blood levels simultaneously. In another study in dogs and rats, raw garlic caused severe mucosal damage ${ }^{(6)}$. In another study, toxic effects of oral and intraperitoneal administration of garlic extracts on lung and liver tissue of rats were studied. Administration of low doses of garlic $(50 \mathrm{mg} / \mathrm{kg})$ to rats either orally or intraperitoneally had no effect on lung and liver tissue as compared with control animals. Administration of higher dose of garlic $(500 \mathrm{mg} / \mathrm{kg})$ resulted in profound changes in lung and liver tissue of rats, indicating dose-related toxicity ${ }^{(116)}$. The toxic effect of a high dose of garlic was further confirmed in another experimental model where 300 and $600 \mathrm{mg}$ of garlic bulb extract was administered to both male and female rats for $21 \mathrm{~d}$, which resulted in

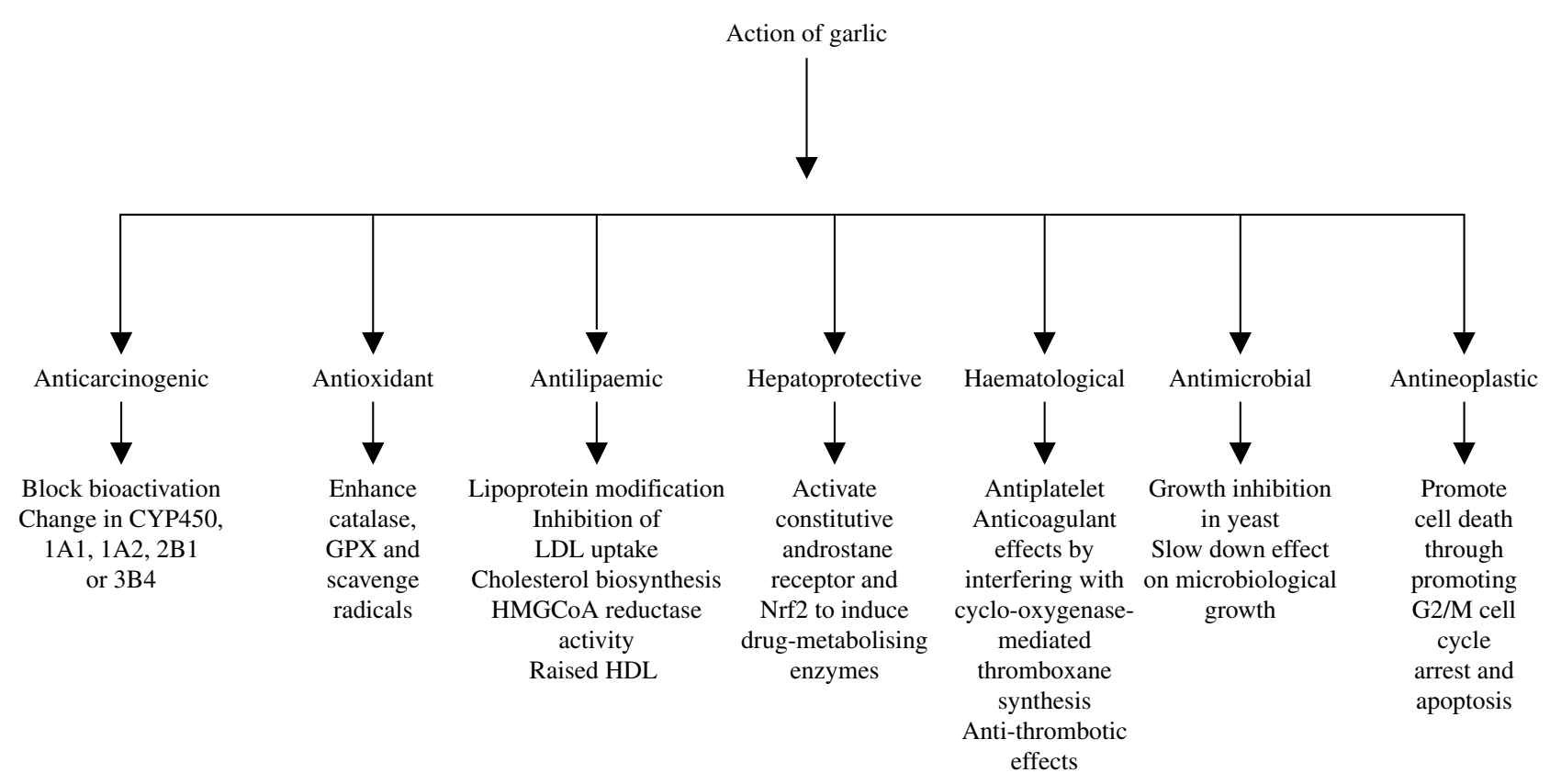

Fig. 2. Summary of the effects of garlic. GPX, glutathione peroxidase; HMG, 3-hydroxy-3-methylglutaryl; Nrf2, nuclear factor E2-related factor 2. 
growth retardation and effects on biological parameters and histological structures ${ }^{(117)}$.

Banerjee et al. ${ }^{(118)}$ investigated long-term effects of a low-dose garlic extract in an animal model using endogenous antioxidant enzymes and lipid peroxidation in the liver and kidney. Rats were fed with fresh garlic homogenate daily in three different doses $(250,500$ and $1000 \mathrm{mg} / \mathrm{kg}$ per d) for $30 \mathrm{~d}$. In comparison with saline-treated rats, the $250 \mathrm{mg} / \mathrm{kg}$ per $\mathrm{d}$ dose resulted in significantly reduced lipid peroxidation and glutathione peroxidase, no change in catalase and reduced glutathione; SOD was increased significantly. Both the 500 and $1000 \mathrm{mg} / \mathrm{kg}$ per d doses significantly reduced endogenous antioxidants (catalase and SOD) without altering lipid peroxidation level. Animals treated with $1000 \mathrm{mg} / \mathrm{kg}$ per d showed morphological changes in the liver both at light microscopy and ultrastructural levels. Histologically, liver showed focal non-specific injury to the hepatocytes. The reason for such type of injuries could be the sulfoxides present in the garlic extract that can undergo exchange reactions with $-\mathrm{SH}$ groups of enzymes and proteins in the body, spontaneously at physiological $\mathrm{pH}$ and temperature, inhibiting their activity $^{(119)}$. Therefore, it seems that garlic in low doses has the potential to enhance the endogenous antioxidant status, although at higher doses a reversal of these effects is observed.

Intraperitoneal and oral administration of high doses ( $5 \mathrm{ml}$ garlic juice $/ \mathrm{kg}$ ) led to weight loss, and hepatic and pulmonary toxicity in rats ${ }^{(120)}$. However, in one study, hypertensive rats given garlic supplements four times daily developed erratic pulses, dehydration, weight loss and lethargy ${ }^{(121)}$.

In humans garlic is considered as safe by the US Food and Drug Administration but is also known to cause gastric irritation if taken in high doses by sensitive individuals. In randomised controlled trials, side effects included heartburn, nausea, vomiting, diarrhoea, flatulence, bloating, mild orthostatic hypotension, flushing, tachycardia, headache, insomnia, sweating and dizziness as well as offensive body odour ${ }^{(122)}$.

\section{Doses of garlic and its compounds}

Yadav et al. ${ }^{(123)}$ have shown that garlic in low doses is safe in frogs. They suggested that garlic extract has some beneficial effects on heart rate, rhythm and force of contraction, but very high doses may exert non-desirable effects as well. The comparative toxic effects of oral and intraperitoneal administration of garlic extracts on lung and liver tissue of rats have also been studied. Administration of a low dose of garlic $(50 \mathrm{mg} / \mathrm{kg}$ per d) to rats either orally or intraperitoneally had little effect on lung and liver tissues as compared with control animals ${ }^{(116)}$. In contrast, administration of a high dose of garlic $(500 \mathrm{mg} / \mathrm{kg}$ per d) resulted in profound changes in lung and liver tissues of rats. Moreover, intraperitoneal administration of a high dose of garlic was more damaging to lung and liver tissues of rats than oral administration. Therefore, these reports highlight some of the adverse and toxic effects of high doses of garlic in animals. In support to this, it has been shown that higher concentrations of garlic extract are clastogenic in mice ${ }^{(124)}$, which was appreciably reduced at lower concentrations. Female and male rats were given 300 and $600 \mathrm{mg} / \mathrm{kg}$ per d of a garlic aqueous extract for $21 \mathrm{~d}$ and the results showed that garlic extract causes toxic effects affecting weight growth, biological parameters and histological structures in rats ${ }^{(117)}$. Banerjee et $a l^{(118)}$ also studied the effects of chronic fresh garlic homogenate in three different doses (250, 500 and $1000 \mathrm{mg} / \mathrm{kg}$ per d) for $30 \mathrm{~d}$ on various endogenous antioxidant enzymes and lipid peroxidation in two major organs, the liver and kidney. It was observed that in comparison with saline-treated rats, the $250 \mathrm{mg} / \mathrm{kg}$ per $\mathrm{d}$ dose significantly reduced the lipid peroxidation levels and increased SOD activity significantly. But higher doses of garlic (500 and $1000 \mathrm{mg} / \mathrm{kg}$ per d) significantly reduced endogenous antioxidants (catalase and SOD) without altering lipid peroxidation levels. A $1000 \mathrm{mg} / \mathrm{kg}$ per d dose of garlic caused marked histopathological and ultrastructural changes in both liver and kidneys. Thus, garlic in low doses has the potential to enhance antioxidant status, although at higher doses a reversal of these effects is observed. Garlic has the potential ability with a high dose to induce morphological changes in the liver and kidneys, indicating the need to identify a safe dose range for garlic. Prolonged feeding of high levels of raw garlic in rats has resulted in anaemia, weight loss and failure to grow due to the lysis of erythrocytes ${ }^{(38)}$. Raw garlic juice at a dose of $5 \mathrm{ml} / \mathrm{kg}$ has resulted in the death of rats due to stomach injury $^{(125)}$. Surviving rats exhibited swelling of the liver, hypertrophy of the spleen and adrenal glands and the decrease of erythrocyte count with various morphological changes after 3 and $8 \mathrm{~d}$. Chen et al. ${ }^{(126)}$ have also reported that treatment of rats with fresh garlic homogenate for $7 \mathrm{~d}$ caused a significant decrease in liver catalase activity in doses of 2 and $4 \mathrm{~g} / \mathrm{kg}$ per $\mathrm{d}$. Garlic oil fed to rats at a dose of $100 \mathrm{mg} / \mathrm{kg}$ per $\mathrm{d}$ in fasting conditions has also been found to be lethal. The cause of death appears to be acute pulmonary oedema with severe congestion ${ }^{(127)}$ Garlic oil and DADS $(200 \mathrm{mg} / \mathrm{kg})$ significantly reduced the body-weight gain of rats ${ }^{(128)}$. One possible explanation for all the above-mentioned toxicity reports is that the sulfoxides present in garlic extract undergo exchange reactions with $-\mathrm{SH}$ groups of enzymes and other proteins in the body at physiological $\mathrm{pH}$ and temperature, so inhibiting their activity ${ }^{(129)}$.

The effect of raw garlic at a dietary dose on platelet function has been studied by Scharbert et al. who reported that single consumption of fresh garlic up to $4 \cdot 2 \mathrm{~g} / \mathrm{d}$ has no inhibitory effect on platelet function in healthy volunteers ${ }^{(130)}$. Gadkari et al. ${ }^{(131)}$ showed increased clotting times from 4.15 to $5.02 \mathrm{~min}$ by investigating the in vivo 
effect of raw garlic intake of $10 \mathrm{~g}$ for 2 months. Asdaq \& Inamdar have concluded that garlic in a moderate dose $(250 \mathrm{mg} / \mathrm{kg})$ with added hydrochlorothiazide possesses synergistic cardioprotective and antihypertensive properties against fructose- and isoproterenol-induced toxicities ${ }^{(132)}$. A dose of garlic homogenate $(250 \mathrm{mg} / \mathrm{kg}$ per d) either alone or with propranolol showed significant increase in activities of antioxidant enzymes such as SOD and catalase during ischaemia-reperfusion injury ${ }^{(133)}$. Satitvipawee et $a{ }^{\left({ }^{(134)}\right.}$ showed no statistically significant changes in serum total cholesterol, TAG, LDL-cholesterol and HDL-cholesterol after 12 weeks of treatment with enteric-coated Thai garlic extract tablet once daily (standardised to $1.12 \%$ allicin or $5.6 \mathrm{mg} /$ tablet). In addition, no changes in plasma glucose, liver and renal functions were found ${ }^{(134)}$

\section{Summary}

In the present review, antioxidant, antilipaemic, hepatoprotective, haematological, antimicrobial and antineoplastic actions of garlic have been shown. The studies reviewed reveal that the benefits of garlic are not limited to a specific species, a particular tissue, or a specific carcinogen. Oil-soluble compounds such as DADS have been observed to be effective in reducing the proliferation of neoplasms. However, it has also been reported that higher concentrations of garlic powder cause considerable cell injury in the liver of rats, which is not observed at lower concentrations.

Thus, although the evidence supports the benefits of garlic, additional evidence is needed to determine the quantity required by humans to minimise cancer, cardiovascular risks and haematological diseases, and to provide hepatoprotection and antilipaemic and antimicrobial effects.

\section{Acknowledgements}

The help of Mr Manu Rana for typing and of Miss Jaspreet Kaur for correcting the manuscript is acknowledged. The typing of this article has been funded by the Department of Gastroenterology, PGIMER, Chandigarh.

All authors have contributed in searching the literature, writing, typing and correcting this article.

There are no conflicts of interests to declare.

\section{References}

1. Fenwick GR \& Hanley AB (1985) The genus Allium. Part 2. Crit Rev Food Sci Nutr 22, 273-277.

2. Matsuura H, Ushiroguchi T, Itakura T, et al. (1988) A furostanol glycoside from garlic bulbs of Allium sativum L. Chem Pharm Bull 36, 3659-3663.

3. Kaku H, Goldstein IJ, Van Damme EJM, et al. (1992) New mannose-specific lectins from garlic (Allium sativum) and ramsons (Allium ursinum) bulbs. Carbohydr Res 229, 347-353.

4. Amagase H, Petesch LB, Matsuura H, et al. (2001) Intake of garlic and its bioactive compounds. J Nutr 31, 955S-962S.

5. Lawson LD \& Gardner CD (2005) Composition, stability, and bioavailability of garlic products used in a clinical trial. J Agric Food Chem 53, 6254-6261.

6. Egen-Schwind C, Eckard R \& Kemper FH (1992) Metabolism of garlic constituents in the isolated perfused rat liver. Planta Medica 58, 301-305.

7. Lachmann G, Horenz D, Radeck W, et al. (1994) The pharmacokinetics of the S-35 labeled garlic constituents alliin, allicin and vinyldithiine (article in German). Arzeimitteforschung 44, 734-743.

8. Su CC, Chen GW, Tan TW, et al. (2006) Crude extract of garlic induced caspase- 3 gene expression leading to apoptosis in human colon cancer cells. In Vivo 20, 85-90.

9. Manson MM, Ball HW, Barrett MC, et al. (1997) Mechanism of action of dietary chemoprotective agents in rat liver: induction of phase I and II drug metabolizing enzymes and aflatoxin B1 metabolism. Carcinogenesis 18, 1729-1738.

10. Wang BH, Zuzel KA, Rahman K, et al. (1999) Treatment with aged garlic extract protects against bromobenzene toxicity to precision cut rat liver slices. Toxicology 132, 215-225.

11. Singh A \& Shukla Y (1998) Antitumor activity of diallyl sulfide in two-stage mouse skin model of carcinogenesis. Biomed Environ Sci 11, 258-263.

12. Hughes MF, Chamulitrat W, Mason RP, et al. (1989) Epoxidation of 7,8-dihydroxy-7,8-dihydrobenzo[a]pyrene via a hydroperoxide-dependent mechanism catalyzed by lipoxygenases. Carcinogenesis 10, 2075-2080.

13. Roy P \& Kulkarni AP (1999) Co-oxidation of acrylonitrile by soybean lipoxygenase and partially purified human lung lipoxygenase. Xenobiotica 29, 511-531.

14. Singh A \& Singh SP (1997) Modulatory potential of smokeless tobacco on the garlic, mace or black mustard-altered hepatic detoxication system enzymes, sulfhydryl content and lipid peroxidation in murine system. Cancer Lett 118, 109-114.

15. Hu X, Benson PJ, Srivastava SK, et al. (1997) Induction of glutathione $S$-transferase $\pi$ as a bioassay for the evaluation of potency of inhibitors of benzo( $a$ ) pyrene-induced cancer in a murine model. Int J Cancer 73, 897-902.

16. Morihara N, Nishihama T, Ushijima M, et al. (2007) Garlic as an anti-fatigue agent. Mol Nutr Food Res 51, 1329-1334.

17. Tattelman E (2005) Health effects of garlic. Am Fam Physician 72, 103-106.

18. Ryzhenkov VE \& Makarov VG (2003) Biologically active substances in garlic (Allium sativum L.) and their application in nutrition for humans (article in Russian). Vopr Pitam 72, 42-46.

19. Ghazanfar SA (1994) Handbook of Arabian Medicinal Plants. Boca Raton, FL: CRC Press.

20. Kapoor LD (1990) CRC Handbook of Ayurvedic Medicinal Plants. Boca Raton, FL: CRC Press.

21. Peirce A (1999) The ABC Clinical Guide to Herbs: The American Pharmaceutical Association Practical Guide to Natural Medicines. New York: William Morrow and Company, Inc.

22. Barnes J, Anderson LA \& Phillipson ID (1996) Herbal Medicines: A Guide for Health-Care Professionals. London: Pharmaceutical Press.

23. Woodward PW (1996) Garlic and Friends: The History, Growth and Use of Edible Alliums. Melbourne: Hyland House Publishing.

24. El Shenawy NS, Soliman MF \& Reyad SI (2008) The effect of antioxidant properties of aqueous garlic extract and 
Nigella sativa as anti-schistosomiasis agents in mice. Rev Inst Med Trop Sao Paulo 50, 29-36.

25. Liu HG \& Xu LH (2007) Garlic oil prevents tributyltininduced oxidative damage in vivo and in vitro. $J$ Food Prot 70, 716-721.

26. Ogita A, Nagao Y, Fujita K, et al. (2007) Amplification of vacuole-targeting fungicidal activity of antibacterial antibiotic polymyxin B by allicin, an allylsulfur compound from garlic. J Antibiot (Tokyo) 60, 511-518.

27. Chan KC, Yin MC \& Chao WJ (2007) Effect of diallyl trisulfide-rich garlic oil on blood coagulation and plasma activity of anticoagulation factors in rats. Food Chem Toxicol 45, 502-507.

28. Kumaraguruparan R, Chandra Mohan KV \& Abraham SK (2005) Attenuation of $N$-methyl- $N^{\prime}$-nitro- $N$-nitrosoguanidine induced genotoxicity and oxidative stress by tomato and garlic combination. Life Sci 76, 2247-2255.

29. Prasad K, Haxdal A, Yu M, et al. (1995) Antioxidant activity of allicin, an active principle in garlic. Mol Cell Biochem 148, 183-189.

30. Imai J, Ide N, Nagae S, et al. (1994) Antioxidant and radical scavenging effects of aged garlic extract and its constituents. Planta Medica 60, 417-420.

31. Melaleb R (1993) Antioxidant, antitumor and cardiovascular actions of garlic. Herbal Gram 29, 18-72.

32. Torok B, Belaggi J \& Reitz B (1994) Effectiveness of garlic on the radical activity in radical generating system. Arzeimittelfrschung 44, 608-611.

33. Chang HS, Yamato O, Yamasaki M, et al. (2005) Modulatory influence of sodium 2-propenyl thiosulfate from garlic on cyclooxygenase activity in canine platelets: possible mechanism for the anti-aggregatory effect. Prostaglandins Leukot Essent Fatty Acids 72, 351-355.

34. Lewin G \& Popev I (1994) Antioxidant effect of aqueous garlic extract. 2nd communication: inhibition of the $\mathrm{Cu}(2+)$-initiated oxidation of low density lipoproteins. Arzneimettelforchung 44, 604-607.

35. Ahmad MS \& Ahmed N (2006) Antiglycation properties of aged garlic extract: possible role in prevention of diabetic complications. J Nutr 136, 796S-799S.

36. Park EY, Ki SH, Ko MS, et al. (2005) Garlic oil and DDB, comprised in a pharmaceutical composition for the treatment of patients with viral hepatitis, prevents acute liver injuries potentiated by glutathione deficiency in rats. Chem Biol Interact 155, 82-96.

37. Sener G, Sehirli O, Ipçi Y, et al. (2005) Aqueous garlic extract alleviates ischaemia-reperfusion-induced oxidative hepatic injury in rats. J Pharm Pharmacol 57, $145-150$.

38. Augusti KT (1996) Therapeutic values of onion (Allium cepa L.) and garlic (Allium sativum L.). Indian J Exp Biol 34, 634-640.

39. Fukao T, Hosono T, Misawa S, et al. (2004) The effects of allyl sulfides on the induction of phase II detoxification enzymes and liver injury by carbon tetrachloride. Food Chem Toxicol 42, 743-749.

40. Arivazhagan S, Velmurugan B, Bhuvaneswari V, et al. (2004) Effects of aqueous extracts of garlic (Allium sativum) and neem (Azadirachta indica) leaf on hepatic and blood oxidant-antioxidant status during experimental gastric carcinogenesis. J Med Food 7, 334-339.

41. Pérez-Severiano S, Rodríguez-Pérez M, Pedraza-Chaverrí J, et al. (2004) S-Allylcysteine, a garlic-derived antioxidant, ameliorates quinolinic acid-induced neurotoxicity and oxidative damage in rats. Neurochem Int 45, 1175-1183.

42. Borek C (2006) Garlic reduces dementia and heart-disease risk. J Nutr 136, 810S-812S.
43. Liu Jz, Lin XY \& Milner JZ (1992) Dietary garlic powder increase glutathione content and glutathione $S$-transferase activity in rat liver and mammary tissues. FASEB $J \mathbf{6}$, A3230-A3231.

44. Wang Z, Peng Z, Keng R, et al. (1998) Effect of allicin in ethanol-induced hepatotoxicity in mice. Wei Sheng Yan Jiu 27, 415-457.

45. Williams MJ, Sutherland WH, McCormick MP, et al. (2005) Aged garlic extract improves endothelial function in men with coronary artery disease. Phytother Res 19 , 314-319.

46. Dhawan V \& Jain S (2004) Effect of garlic supplementation on oxidized low density lipoproteins and lipid peroxidation in patients of essential hypertension. Mol Cell Biochem 266, $109-115$.

47. Khanum F, Anilakumar KR \& Viswanatham KR (2004) Anticarcinogenic properties of garlic: a review. Crit Rev Food Sci Nutr 44, 479-488.

48. Durak I, Aytac B, Atmaca Y, et al. (2004) Effects of garlic extract consumption in plasma and erythrocyte antioxidant parameters in atherosclerotic patients. Life Sci 75, 1957-1966.

49. Zahid AM, Hussain ME \& Fahim M (2005) Antiatherosclerotic effects of dietary supplementations of garlic and turmeric: restoration of endothelial function in rats. Life Sci 77, 837-857.

50. Gonen A, Harats D, Rabinkov A, et al. (2005) The antiatherogenic effect of allicin: possible mode of action. Pathobiology 72, 325-334.

51. Gebhardt R \& Beck H (1996) Differential inhibitory effects of garlic-derived organosulfur compounds on cholesterol biosynthesis in primary rat hepatocyte cultures. Lipids 31, 1269-1276.

52. Larner AJ (1995) How does garlic exert its hypocholesterolaemic action? The tellurium hypothesis. Med Hypotheses 44, 295-307.

53. Yeh YY \& Liu L (2001) Cholesterol lowering effect of garlic extracts and organosulfur compounds: human and animal studies. J Nutr 131, 989S-993S.

54. Mathew BC, Daniel RS \& Augusti KT (1996) Hypolipidemic effect of garlic protein substituted for casein in diet of rats compared to those of garlic oil. Indian J Exp Biol 34, 337-340.

55. Chetty KN, Calaham L, Harris KC, et al. (2003) Garlic attenuates hypercholesterolemic risk factors in olive oil fed rats and high cholesterol fed rats. Pathophysiology 9, 127-132.

56. Chowdhury SR, Chowdhury SD \& Smith TK (2002) Effects of dietary garlic on cholesterol metabolism in laying hens. Poult Sci 81, 1856-1862.

57. Liu L \& Yeh YY (2002) S-alk(en)ylcysteines of garlic inhibit cholesterol synthesis by deactivating HMG-CoA reductase in cultured rat hepatocytes. J Nutr $\mathbf{1 3 2}$ 1129-1144.

58. Kweon MJ, Song YS, Choi MS, et al. (2003) Cholesteryl ester transfer protein activity and atherogenic parameters in rabbits supplemented with cholesterol and garlic powder. Life Sci 72, 2953-2964.

59. Hsu CC, Huang CN, Hung YC, et al. (2004) Five cysteinecontaining compounds have antioxidative activity in Balb/cA mice. J Nutr 134, 149-152.

60. Ahmed RS \& Sharma SB (1997) Biochemical studies on combined effects of garlic (Allium sativum Linn) and ginger (Zingiber officinale Rosc) in albino rats. Indian $J$ Exp Biol 35, 841-843.

61. Silagy C \& Neil A (1994) Garlic as a lipid lowering agent - a meta-analysis. J R Coll Physicians Lond 28, 39-45. 
62. Jain AK, Varges R, Gotzkowsky S, et al. (1993) Can garlic reduce levels of serum lipids? A controlled clinical study. Am J Med 94, 632-635.

63. Campbell JH, Efendy JL, Smith NJ, et al. (2001) Molecular basis by which garlic suppresses atherosclerosis. J Nutr 131, 1006S-1009S.

64. Ismail MF, Gad MZ \& Handy MA (1999) Study of the hypolipidemic properties of pectin, garlic and ginseng in hypercholesterolemic rabbits. Pharmacol Res 39. 157-166.

65. Jung F, Jung EM, Mrowietz C, et al. (1990) Influence of garlic powder on cutaneous microcirculation: a randomized, placebo-controlled, double-blind, crossover study in apparently healthy subjects. Br J Clin Pract 69, 30-35.

66. Siegel G, Walter A, Engel S, et al. (1999) Pleiotropic effects of garlic. Wien Med Wochenschr 149, 217-224.

67. Fisher CD, Augustine LM, Maher JM, et al. (2007) Induction of drug-metabolizing enzymes by garlic and allyl sulfide compounds via activation of constitutive androstane receptor and nuclear factor E2-related factor 2. Drug Metab Dispos 35, 995-1000.

68. Kodai S, Takemura S, Minamiyama Y, et al. (2007) S-allyl cysteine prevents $\mathrm{CCl}_{4}$-induced acute liver injury in rats. Free Radic Res 41, 489-497.

69. Pal R, Vaiphei K, Sikander A, et al. (2006) Effect of garlic on isoniazid and rifampicin-induced hepatic injury in rats. World J Gastroenterol 12, 636-639.

70. Fancelli SL, Castro GD, de Toranzo FG, et al. (1998) Mechanisms of the preventive properties of some garlic components in the carbon tetrachloride-promoted oxidative stress. Diallyl sulfide; diallyl disulfide; allyl mercaptan and allyl methyl sulfide. Res Commun Mol Pathol Pharmacol 102, 163-174.

71. Senapati SK, Dey S, Dwivedi SK, et al. (2001) Effect of garlic (Allium sativum L.) extract on tissue lead level in rats. J Ethnopharmacol 76, 229-232.

72. Arora A, Seth K \& Shukla Y (2004) Reversal of P-glycoprotein-mediated multidrug resistance by diallyl sulfide in K562 leukemic cells and in mouse liver. Carcinogenesis 25, 941-949.

73. Bergès R, Siess MH, Arnault J, et al. (2004) Comparison of the chemopreventive efficacies of garlic powders with different alliin contents against aflatoxin B1 carcinogenicity in rats. Carcinogenesis 25, 1953-1959.

74. Kalantari H \& Salehi M (2001) The protective effect of garlic oil on hepatotoxicity induced by acetaminophen in mice and comparison with $\mathrm{N}$-acetylcysteine. Saudi Med J 22, $1080-1084$

75. Sheweita SA, Abd El-Gabar M \& Bastawy M (2001) Carbon tetrachloride induced changes in the activity of phase II drug metabolizing enzymes in the liver of male rats: role of antioxidants. Toxicology 165, 217-224.

76. Gedik N, Kabasakal L, Sehirli O, et al. (2005) Long-term administration of aqueous garlic extract (AGE) alleviates liver fibrosis and oxidative damage induced by biliary obstruction in rats. Life Sci 76, 2593-2606.

77. Caldwell SH, Jeffers LI, Narula OS, et al. (1992) Ancient remedies revisited: does Allium sativum (garlic) palliate the hepatopulmonary syndrome? J Clin Gastroenterol 15, $248-250$

78. Pearson W, Charch A, Brewer D, et al. (2007) Pilot study investigating the ability of an herbal composite to alleviate clinical signs of respiratory dysfunction in horses with recurrent airway obstruction. Can J Vet Res 71, 145-151.

79. Wojcikowski K, Myers S \& Brooks L (2007) Effects of garlic oil on platelet aggregation: a double-blind placebocontrolled crossover study. Platelets 18, 29-34.
80. MacDonald JA, Marchand ME \& Langler RF (2004) Improving upon the in vitro biological activity of antithrombotic disulfides. Blood Coagul Fibrinolysis 15, 447-450.

81. Ide N, Keller C \& Weiss N (2006) Aged garlic extract inhibits homocysteine-induced CD36 expression and foam cell formation in human macrophages. I Nutr 136, 755S-757S.

82. Chung I, Kwon SH, Shim ST, et al. (2007) Synergistic antiyeast activity of garlic oil and allyl alcohol derived from alliin in garlic. J Food Sci 72, M437-M440.

83. Eja ME, Asikong BE, Abriba C, et al. (2007) A comparative assessment of the antimicrobial effects of garlic (Allium sativum) and antibiotics on diarrheagenic organisms. Southeast Asian I Trop Med Public Health 38, 343-348.

84. Al-Waili NS, Saloom KY, Akmal M, et al. (2007) Effects of heating, storage, and ultraviolet exposure on antimicrobial activity of garlic juice. J Med Food 10, 208-212.

85. Aydin A, Bostan K, Erkan ME, et al. (2007) The antimicrobial effects of chopped garlic in ground beef and raw meatball (ciğ köfte). J Med Food 10, 203-207.

86. Groppo FC, Ramacciato JC, Motta RH, et al. (2007) Antimicrobial activity of garlic against oral streptococci. Int J Dent Hyg 5, 109-115.

87. Sallam KI, Ishioroshi M \& Samejima K (2007) Antioxidant and antimicrobial effects of garlic in chicken sausage. Lebenson Wiss Technol 37, 849-855.

88. Konaklieva MI \& Plotkin BJ (2006) Antimicrobial properties of organosulfur anti-infectives: a review of patent literature 1999-2005. Recent Patents Anti-Infect Drug Disc 1, $177-180$.

89. Amin M \& Kapadnis BP (2005) Heat stable antimicrobial activity of Allium ascalonicum against bacteria and fungi. Indian J Exp Biol 43, 751-754.

90. Maldonado PD, Chanez CME \& Pedraza CJ (2005) Aged garlic extract, garlic-powder extract, $S$-allylcysteine, diallyl sulfide and diallyl disulfide do not interfere with the antibiotic activity of gentamicin. Phytother Res 19, 252-254.

91. Cañizares P, Gracia I, Gómez LA, et al. (2004) Allylthiosulfinates, the bacteriostatic compounds of garlic against Helicobacter pylori. Biotechnol Prog 20, 397-401.

92. Sivam GP, Lampe JW, Ulness B, et al. (1997) Helicobacter pylori - in vitro susceptibility to garlic (Allium sativum) extract. Nutr Cancer 27, 118-121.

93. Cellini L, Di Campli E, Masulli M, et al. (1996) Inhibition of Helicobacter pylori by garlic extract (Allium sativum). FEMS Immunol Med Microbial 13, 273-277.

94. Chowdhury AK, Ahsam M, Islam SN, et al. (1991) Efficacy of aqueous extract of garlic and allicin in experimental shigellosis in rabbits. Indian J Med Res 93, 33-36.

95. Howard EW, Lee DT, Chiu YT, et al. (2008) Evidence of a novel docetaxel sensitizer, garlic-derived $S$-allylmercaptocysteine, as a treatment option for hormone refractory prostate cancer. Int J Cancer 122, 1941-1948.

96. Jo HJ, Song JD, Kim KM, et al. (2008) Diallyl disulfide induces reversible $\mathrm{G} 2 / \mathrm{M}$ phase arrest on a p53-independent mechanism in human colon cancer HCT-116 cells. Oncol Rep 19, 275-280.

97. Devrim E \& Durak I (2007) Is garlic a promising food for benign prostatic hyperplasia and prostate cancer? Mol Nutr Food Res 51, 1319-1323.

98. Nigam N \& Shukla Y (2007) Preventive effects of diallyl sulfide on 7,12-dimethylbenz[a]anthracene induced DNA alkylation damage in mouse skin. Mol Nutr Food Res 51, 1324-1328.

99. Kaur P \& Singh R (2007) In vivo interactive effect of garlic oil and vitamin $\mathrm{E}$ against stavudine induced genotoxicity in Mus musculus. Indian J Exp Biol 45, 807-811. 
100. Lu HF, Yang JS, Lin YT, et al. (2007) Diallyl disulfide induced signal transducer and activator of transcription 1 expression in human colon cancer colo 205 cells using differential display RT-PCR. Cancer Genomics Proteomics 4, 93-97.

101. Zhang ZM, Yang XY, Deng SH, et al. (2007) Anti-tumor effects of polybutylcyanoacrylate nanoparticles of diallyl trisulfide on orthotopic transplantation tumor model of hepatocellular carcinoma in BALB/c nude mice. Chin Med $J$ (Engl) 120, 1336-1342.

102. Das A, Banik NL \& Ray SK (2007) Garlic compounds generate reactive oxygen species leading to activation of stress kinases and cysteine proteases for apoptosis in human glioblastoma T98G and U87MG cells. Cancer 110, 1083-1095.

103. Khan A, Shukla Y, Kalra N, et al. (2007) Potential of diallyl sulfide bearing $\mathrm{pH}$-sensitive liposomes in chemoprevention against DMBA-induced skin papilloma. Mol Med 13, 443-451.

104. Iciek M, Marcinek J, Mleczko U, et al. (2007) Selective effects of diallyl disulfide, a sulfane sulfur precursor, in the liver and Ehrlich ascites tumor cells. Eur J Pharmacol 569, $1-7$.

105. Lemar KM, Aon MA, Cortassa S, et al. (2007) Diallyl disulphide depletes glutathione in Candida albicans: oxidative stress-mediated cell death studied by two-photon microscopy. Yeast 24, 695-706.

106. Terrasson J, Xu B, Li M, et al. (2007) Activities of Z-ajoene against tumour and viral spreading in vitro. Fundam Clin Pharmacol 21, 281-289.

107. Agarwal MK, Iqbal M \& Athar M (2007) Garlic oil ameliorates ferric nitrilotriacetate (Fe-NTA)-induced damage and tumor promotion: implications for cancer prevention. Food Chem Toxicol 45, 1634-1640.

108. Schulz M, Lahmann PH, Boeing H, et al. (2005) Fruit and vegetable consumption and risk of epithelial ovarian cancer. The European Prospective Investigation into Cancer and Nutrition. Cancer Epidemol Biomarkers Prev 14, 2531-2535.

109. Bose C, Guo J, Zimniak L, et al. (2002) Critical role of allyl groups and disulfide chain in induction of $\mathrm{Pi}$ class glutathione transferase in mouse tissues in vivo by diallyl disulfide, a naturally occurring chemopreventive agent in garlic. Carcinogenesis 23, 1661-1665.

110. Hu DJ (1990) Protective effect of diallyl sulfide, a natural extract of garlic, on MNNG-induced damage of rat glandular stomach mucosa. Zhonghua Zhonghua Zhong Liu Za Zhi 12, 429-431.

111. Srivastava SK, Hu X, Xia H, et al. (1997) Mechanism of differential efficacy of garlic organosulfides in preventing benzo(a)pyrene-induced cancer in mice. Cancer Lett 118, 61-67.

112. Ip C \& Disk DJ (1997) Modulation of phase I and phase II xenobiotic-metabolizing enzymes by selenium-enriched garlic in rats. Nutr Cancer 28, 184-188.

113. Augusti KT \& Mathew PT (1975) Effect of allicin on certain enzymes of liver after a short term feeding to normal rats. Experientia 31, 148-149.

114. Dixit VP \& Joshi S (1982) Effects of chronic administration of garlic (Allium sativum Linn) on testicular function. Indian J Exp Biol 20, 534-566.

115. Egen-Schwind C, Eckard R, Jekat FW, et al. (1992) Pharmacokinetics of vinyldithiins, transformation products of allicin. Planta Med 58, 8-13.

116. Alnaqeeb MA, Thomson M, Bordia T, et al. (1996) Histopathological effects of garlic on liver and lung of rats. Toxicol Lett 85, 157-164.
117. Fehri M, Aiache JM, Korbi S, et al. (1991) Toxic effects induced by the repeat administration of Allium sativum $\mathrm{L}$. J Pharm Belg 46, 363-374.

118. Banerjee SK, Maulik M, Manchanda SC, et al. (2001) Garlic-induced alteration in rat liver and kidney morphology and associated changes in endogenous antioxidant status. Food Chem Toxicol 39, 793-797.

119. Jocelyn PC (1972) Biochemistry of the SH Group: The Occurrence, Chemical Properties, Metabolism and Biological Functions of Thiols and Disulphides, p. 107. New York: Academic Press.

120. Shashikanth KN, Basappa SC \& Sreenivasa Murthy VA (1984) A comparative study of raw garlic extract and tetracycline on caecal microflora and serum proteins of albino rats. Folia Microbial 29, 348-352.

121. Ruffin J \& Hunter SA (1983) An evaluation of the side effects of garlic as an antihypertensive agent. Cytobios 37, 85-89.

122. Desai HG, Kalro RH \& Choksi AP (1990) Effect of ginger and garlic on DNA content of gastric aspirate. Indian $J$ Med Res 92, 139-141.

123. Yadav RK \& Verma NS (2004) Effects of garlic (Allium sativum) extract on the heart rate, rhythm and force of contraction in frog: a dose dependent study. Indian J Exp Biol 42, 628-631.

124. Das T, Roychoudhury A, Sharma A, et al. (1996) Effects of crude garlic extract on mouse chromosomes in vivo. Food Chem Toxicol 34, 43-47.

125. Nakagawa S, Masamoto K, Sumiyoshi H, et al. (1980) Effect of raw and extracted-aged garlic juice on growth of young rats and their organs after peroral administration (article in Japanese). J Toxicol Sci 5, 91-112.

126. Chen L, Hong JY, So E, et al. (1999) Decrease of hepatic catalase level by treatment with diallyl sulfide and garlic homogenates in rats and mice. J Biochem Mol Toxicol 13 $127-133$.

127. Joseph PK, Rao KR \& Sundaresh CS (1989) Toxic effects of garlic extract and garlic oil in rats. Indian J Exp Biol 27, 977-979.

128. Sheen LY, Chen HW, Kung YL, et al. (1999) Effects of garlic oil and its organosulfur compounds on the activities of hepatic drug-metabolizing and antioxidant enzymes in rats fed high- and low-fat diets. Nutr Cancer 35, $160-166$.

129. Banerjee SK \& Maulik SK (2002) Effect of garlic on cardiovascular disorders: a review. Nutr J 1, 4.

130. Scharbert G, Kalb ML, Duris M, et al. (2007) Garlic at dietary doses does not impair platelet function. Anesth Analg 105, 1214-1218.

131. Gadkari JV \& Joshi VD (1991) Effect of ingestion of raw garlic on serum cholesterol level, clotting time and fibrinolytic activity in normal subjects. J Postgrad Med 37, 128-131.

132. Asdaq SM \& Inamdar MN (2011) The potential benefits of a garlic and hydrochlorothiazide combination as antihypertensive and cardioprotective in rats. $J$ Nat $\mathrm{Med}$ 65, 81-88.

133. Asdaq SM, Inamdar MN \& Asad M (2010) Pharmacodynamic interaction of garlic with propranolol in ischemiareperfusion induced myocardial damage. Pak J Pharm Sci 23, 42-47.

134. Satitvipawee P, Rawdaree P, Indrabhakti S, et al. (2003) No effect of garlic extract supplement on serum lipid levels in hypercholesterolemic subjects. J Med Assoc Thai 86, 750-757. 